\title{
Diagnosis of GATA2 haplo-insufficiency in a young woman prompted by pancytopenia with deficiencies of B-cell and dendritic cell development
}

\author{
Allen Sanyi ${ }^{1}$, David L. Jaye ${ }^{2}$, Cecilia B. Rosand ${ }^{3}$, Amanda Box ${ }^{3}$, Chandrakasan Shanmuganathan ${ }^{4}$ \\ and Edmund K. Waller ${ }^{3,5^{*}}$
}

\begin{abstract}
Background: GATA2 deficiency presents with a spectrum of phenotypes including increased susceptibility to viral and bacterial infections, multi-lineage cytopenias, aplastic anemia, leukemic transformation and lymphedema. Allogeneic transplantation is only curative therapy for GATA2 deficiency, but is associated with significant treatment related morbidity and mortality. Given the spectrum of clinical presentation, accurate diagnosis of GATA2 deficiency is necessary to identify patients early in their disease course when allogeneic bone marrow transplantation may be of clinical benefit.

Case presentation: In this report, we present a GATA2 mutation diagnosed in 23-year-old woman presenting with pancytopenia, recurring oral blisters, fatigue and chronic pain. We describe markedly low levels of mature B-cells in the blood and bone marrow and the absence of detectable blood dendritic cells with normal serum immunoglobulin levels and normal numbers of marrow plasma cells. She was ultimately diagnosed with GATA2 haplo-insufficiency due to a GATA2 germ-line mutation and underwent a successful allogeneic bone marrow transplant from a 10/10 HLA matched unrelated donor.

Conclusions: The case illustrates the diagnostic difficulties in identifying GATA2 deficiencies and the importance of family history and genetic testing. GATA2 plays an important role in B-cell and dendritic cell development, and decreased numbers of those cells is a characteristic feature that should prompt consideration of GATA2 deficiency in a patient with pancytopenia. Maturation of B-cells to long-lived plasma cells is relatively unaffected in GATA2 deficiency. Allogeneic stem cell transplantation can correct immune-deficiencies and prevent leukemic transformation in patients with GATA2 deficiency.
\end{abstract}

Keywords: GATA2 deficiency, Bone marrow failure, B-cell deficiency, Allogeneic transplant

\section{Background}

GATA2 is a zinc finger transcription factor that is a critical regulator of gene expression in hematopoietic cells [1]. GATA 2 haplo-insufficiency is a rare germline condition that results from heterozygous mutations in the promoter region or coding sequence of the GATA2 gene which can either lead to protein dysfunction or uniallelic

\footnotetext{
* Correspondence: ewaller@emory.edu

${ }^{3}$ Winship Cancer Institute, Emory University, Atlanta, GA 30322, USA

${ }^{5}$ Department of Hematology/Oncology, and Pathology, Bone Marrow and Stem Cell transplantation, Emory University School of Medicine, 1365B Clifton Road, Suite B5119, Atlanta, GA 30322, USA

Full list of author information is available at the end of the article
}

reduced GATA2 mRNA transcription. The consequence of reduced levels of functional GATA2 protein include a spectrum of hematological, infectious, pulmonary and dermatologic conditions that typically present in children or young adults with clinical manifestations of multilineage cytopenia, immunodeficiency with increased susceptibility to viral and non-tuberculous mycobacterial infections, pulmonary alveolar proteinosis and peripheral lymphedema, with decreased B-cells, monocytes, dendritic cells and NK cells in the blood and marrow $[2,3]$. The relative deficit of GATA2 during hematopoiesis contributes to the development of aplastic anemia, 
myelodysplasia, and acute leukemia [2, 3]. The molecular basis for GATA2 deficiency includes a variety of germ-line mutations involving the GATA2 locus on chromosome 3 leading to loss of one of the functional GATA2 genes or reductions in GATA2 mRNA transcription. Homozygous deficiency of GATA2 is embryonically lethal early in gestation in mice [4] while conditional knock-out of GATA2 in adult mice leads to pancytopenia with loss of hematopoietic progenitors and dendritic cells [5]. The nature of germline mutations follows an autosomal dominant pattern with diagnostic confirmation by genetic testing. The protean manifestations in phenotype encompass immune deficiencies and cytopenias, and a broad range of age at presentation (13-74 years). Such manifestations coupled with the rareness of the mutation make GATA2 deficiency difficult to diagnose and illustrate the necessity of a high clinical suspicion [2]. To date, allogeneic bone marrow transplantation (BMT) is the only potentially curative treatment for GATA2 deficiency. Patients with GATA2 deficiency should be offered allogeneic bone marrow transplantation prior to the development of fatal cytopenias, chronic infections due to immune-deficiency, or leukemic transformation. While allogeneic BMT may still be curative in GATA2-deficient patients who develop MDS and AML, the efficacy and safety of transplant is higher if it is performed earlier in the natural history of this complex disorder, prompting consideration of GATA2 deficiency in the differential diagnosis of a patient who presents with cytopenia and immunodeficiency.

In this report, we describe clinical manifestations and treatment of a woman with GATA2 deficiency who presented with a history of pancytopenia, recurrent oral ulcers, fatigue and chronic pain.

\section{Case presentation}

A 19-year-old white female presented to a hematology clinic for further evaluation and management of aplastic anemia. At age 9, she began menstruation with heavy bleeding. At age 13, she was found to have low platelet counts around $20 \times 10^{3} / \mu \mathrm{L}$. At age 14, she was diagnosed with mild aplastic anemia based upon a bone marrow biopsy showing a hypocellular marrow without morphological or immunophenotypic evidence for leukemia or myelodysplasia. Her only transfusion history was 2 units of packed red blood cells for worsened anemia related to menorrhagia at age $16(\mathrm{Hgb}$ of $9.9 \mathrm{~g} / \mathrm{dL})$, and she received no specific therapy for aplastic anemia for the next 3 years. In addition to anemia, she complained of frequent sinus and urinary tract infections. She had no history of tobacco use, alcohol consumption, or illicit substance use. A family history revealed a maternal grandmother with a diagnosis of systemic lupus erythematosus, and that both sisters of her maternalgrandmother had anemia with chronically low leukocyte and platelet counts, but no documented immune disorders. A maternal great-grandmother had Charcot-MarieTooth syndrome and died at age 32 of renal failure. The patient's mother, age 48, received 2 units' whole blood 5 years earlier for treatment of anemia. Additionally, her mother had 2 sisters ages 42 and 45, both of whom had anemia, chronic low blood counts, and autoimmune disease (Fig. 1). There was no history of leukemia in the patient's family history. There was no clear diagnosis to explain her anemia, thrombocytopenia and leukopenia, and marrow studies that failed to document AML or MDS. She was given empiric supplemental oral iron $325 \mathrm{mg}$ three times a day, vitamin B12 $1000 \mathrm{mcg}$ daily,

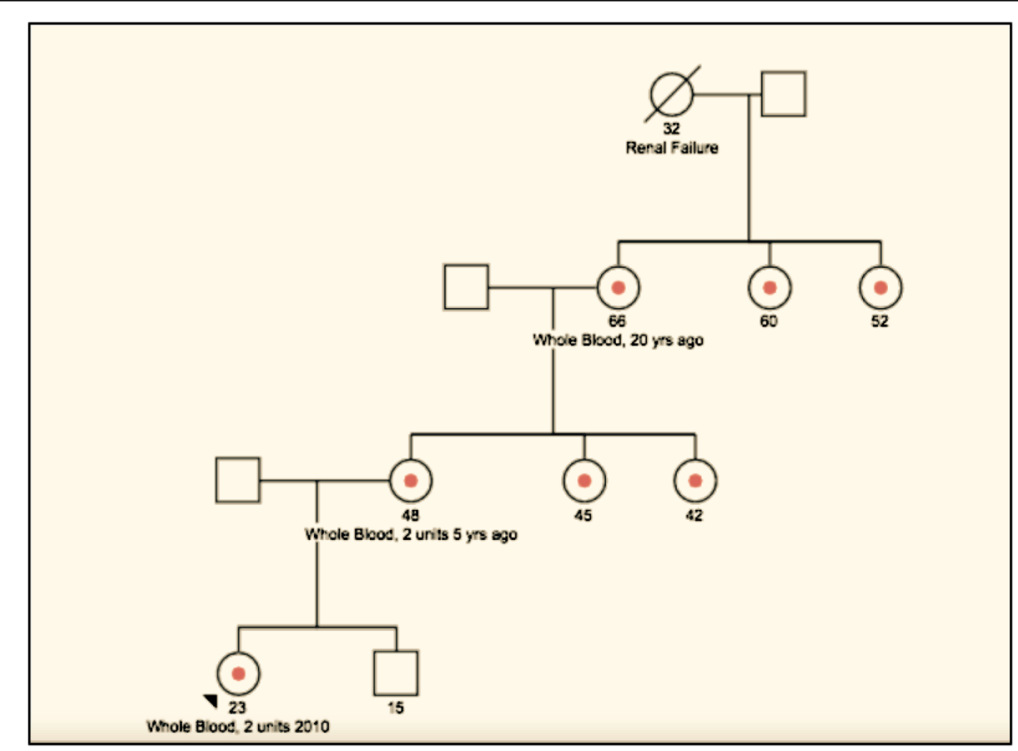

Fig. 1 Pedigree of the affected family. Arrow indicates the patient of discussion 
and folate $1 \mathrm{mg}$ daily without any significant change in her symptoms or blood counts. She was then selfreferred to our center for further evaluation and diagnosis of her hematological abnormalities.

Upon presentation, physical examination showed a normal appearing Caucasian young woman, with mild bruising to her upper extremities, a normal pulmonary and cardiac exam, normal abdominal exam, with no palpable lymphadenopathy or splenomegaly. Positive clinical findings included diffuse superficial apthous-like ulcers in her mouth, vagina, and nasopharynx. A complete blood count showed a low WBC $(2.2 \times 103 / \mathrm{uL})$ with absolute neutropenia (absolute neutrophil count of 140 cells/uL), an absolute monocyte of $0.14 \times 103 / \mathrm{uL}$, a hemoglobin of $11 \mathrm{~g} \%$, RBC count of $3.1 \times 10 \mathrm{E} 6 / \mu \mathrm{l}$ with a MCV of $100 \mathrm{fL}$. She was thrombocytopenic, but transfusion independent, with a platelet count of $29 \times 10 \mathrm{E} 3 / \mu \mathrm{l}$ (Table 1). The peripheral blood smear showed pseudo-Pelger Huet forms and rare hypogranular neutrophils while red cell morphology showed anisopoikilocytosis, elliptocytes and dacryocytes. Blood levels of vitamin B12 (295 pg/mL), folate $(>20.0 \mathrm{ng} / \mathrm{mL})$, and copper $(162 \mathrm{mcg} / \mathrm{dL})$ were in the normal range, with mild iron deficiency (serum iron 28 $\mathrm{mcg} / \mathrm{dL}$, normal range for women $55-160 \mu \mathrm{g} / \mathrm{dL}$ ). HLA typing was ordered for possible allogeneic transplant should her hematological parameters worsen and she became transfusion dependent. Her oral ulcers were treated with acyclovir for presumed HSV infection, however, a throat culture for HSV was negative. She was followed clinically for a year with no substantial change in her blood counts but with worsening constitutional symptoms (Table 2).

A second bone marrow biopsy performed at age 20 (Fig. 2) showed a hypocellular marrow with mild erythroid and myeloid atypia and atypical megakaryocytes

Table 1 Complete blood count and differential table at age 22

\begin{tabular}{lll}
\hline $\begin{array}{l}\text { Complete Blood Counts } \\
\text { and Differential }\end{array}$ & Values & Reference Range \\
\hline White Blood Cell Count & $2.2 \times 10^{3} / \mathrm{uL}$ & $4-10 \times 10^{3} / \mathrm{uL}$ \\
Red Blood Cell Count & $3.22 \times 10^{6} / \mathrm{uL}$ & $3.93-5.22 \times 10^{6} / \mathrm{uL}$ \\
Hemoglobin & $11 \mathrm{~g} / \mathrm{dL}$ & $11.4-14.4 \mathrm{~g} / \mathrm{dL}$ \\
MCV & $100 \mathrm{fL}$ & $79.4-94.8 \mathrm{fL}$ \\
MCH & $34.4 \mathrm{pg}$ & $25.6-32.2 \mathrm{pg}$ \\
MCHC & $34.3 \mathrm{~g} / \mathrm{dL}$ & $30.0-36.0 \mathrm{~g} / \mathrm{dL}$ \\
Hematocrit & $31.8 \%$ & $33.3-41.4 \%$ \\
Platelet Count & $29 \times 10^{3} / \mathrm{uL}$ & $150-400 \times 10^{3} / \mathrm{uL}$ \\
Neutrophil (Differential) & $25 \%$ & $36-75 \%$ \\
Lymphocyte (Differential) & $68 \%$ & $27-47 \%$ \\
Absolute Neutrophil & $0.14 \times 10^{3} / \mathrm{uL}$ & $0.91-5.5 \times 10^{3} / \mathrm{uL}$ \\
Absolute Lymphocyte & $1.48 \times 10^{3} / \mathrm{uL}$ & $0.65-3.05 \times 10^{3} / \mathrm{uL}$ \\
Absolute Monocyte & $0.14 \times 10^{3} / \mathrm{uL}$ & $0.16-0.72 \times 10^{3} / \mathrm{uL}$ \\
\hline
\end{tabular}

Table 2 Serum immunoglobulin levels

\begin{tabular}{llll}
\hline Dates & $\operatorname{lgG}(620-1400)$ & $\operatorname{lgA}(80-350)$ & $\operatorname{lgM}(45-250)$ \\
\hline $6 / 12 / 14$ & $1040 \mathrm{mg} / \mathrm{dL}$ & $77 \mathrm{mg} / \mathrm{dL}$ & $98 \mathrm{mg} / \mathrm{dL}$ \\
$6 / 5 / 17$ & $1120 \mathrm{mg} / \mathrm{dL}$ & $65 \mathrm{mg} / \mathrm{dL}$ & $70 \mathrm{mg} / \mathrm{dL}$ \\
\hline
\end{tabular}

without increased myeloblasts or abnormal cytogenetics. Flow cytometry of the marrow aspirate failed to identify any abnormal cell populations. Immunohistochemistry of the marrow biopsy showed abundant CD3 positive $\mathrm{T}$ cells, while CD138 positive plasma cells and CD20 positive B cells each comprised about $1 \%$ of nucleated cells She had findings consistent with chronic inflammation/ immune activation as evidenced by a mildly elevated CRP of $10.3 \mathrm{mg} / \mathrm{L}$ (normal range $0.3-8 \mathrm{mg} / \mathrm{L}$ ) and elevated IL-6124 pg/ml (normal value $<5 \mathrm{pg} / \mathrm{ml}$ ). No obvious infectious etiology was identified. Repeat laboratory testing showed evidence showed decreased CD107a expression on NK cells indicating abnormal degranulation, suggestive of hemophagocytic lymphohistiocytosis (HLH) [6]. Based on persistent cytopenia, and evidence of chronic inflammation and immune activation, low grade MDS, aplastic anemia, immunodeficiency and HLH were the leading differential diagnosis considered. However, serum ferritin was $12 \mu \mathrm{g} / \mathrm{L}$, not markedly elevated as would be expected for HLH making this diagnosis an unlikely cause of her chronic inflammation or pancytopenia. She was started on a trial of Cyclosporine $200 \mathrm{mg}$ BID (steroids not given) as immunosuppression for treatment of possible aplastic anemia, but this was discontinued after a month due to intolerance and absence of hematological improvement. Additionally, she did not have stigmata of congenital bone marrow failure syndromes such as short stature, skeletal abnormality, or skin hyperpigmentation.

Evaluation for potential immune defect showed a normal levels of serum immunoglobulins. Immunophenotyping of blood and bone marrow by flow cytometry showed decreased B-cells (2.5\% CD19-positive cells), non-detectable plasmacytoid and classical dendritic cells (DC), but normal levels of CD4+ and CD8+ T-cells (Table 3 and Fig. 3). The presence of normal immunoglobulin levels and normal $\mathrm{T}$ cell numbers with absence of recurrent or opportunistic infectious ruled out diagnosis of late onset combined $\mathrm{T}$ and $\mathrm{B}$ cell immune defects and common variable immune deficiency [7]. The presence of peripheral blood monocytopenia with marked B cell lymphocytopenia and absence of DC in a setting of hypocellular marrow, a diagnosis of GATA2 was considered. Polymerase chain reaction basedsequence analysis of GATA2 revealed a heterozygous missense mutation in Allele 1: c.1061C $>\mathrm{T}$ (p.t354 M) that has been previously described for this condition [3]. Although the patient's parents were not tested, her 


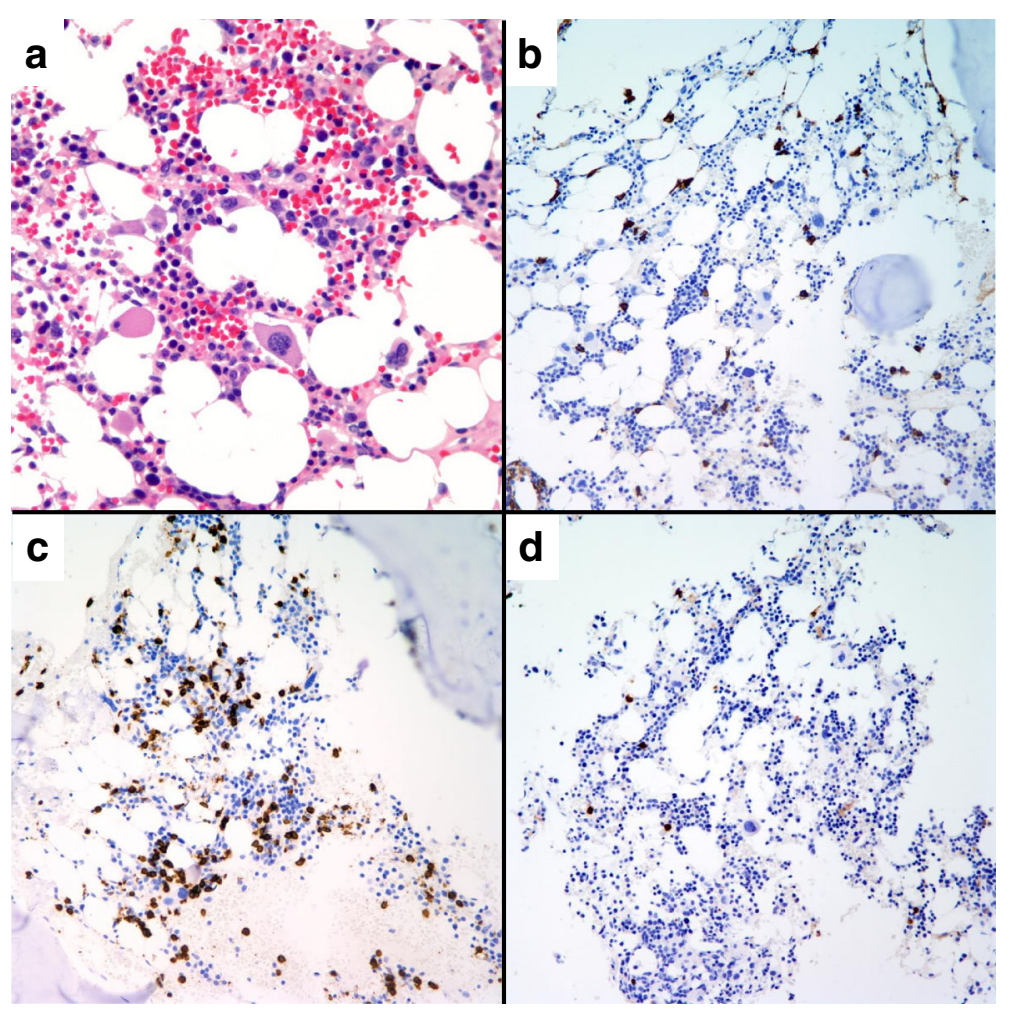

Fig. 2 Bone marrow biopsy showing increased fat and decreased cellularity with relative paucity of normal B-cells. a H\&E (100x). b IHC CD138 (200X), occasional plasmacytoid reactive cells. c $1 \mathrm{HC}$ CD3 (200x), numerous small immunoreactive cells. d IHC CD20 (200x), scattered small immunoreactive cells

family history suggested an autosomal dominant pattern of inheritance affecting her mother and mother's relatives, who appeared to have a mild presentation of the same disorder that affected the patient. With no related HLA-matched sibling or haploidentical donor available, a suitable 10/10 HLA-matched unrelated donor was identified in the NMDP database. After a careful discussion of the natural history of GATA2 deficiency and the risks and benefits of allogeneic transplant, the patient underwent allogeneic BMT from a 10/10 HLA matched unrelated donor following a myeloablative conditioning regimen of busulfan, fludarabine and low dose rabbit ATG [8]. She received post-transplant immunoprophylaxis with methotrexate and tacrolimus and engrafted with neutrophils on day +18 and platelets on day +37 , achieving 100\% donor myeloid and 99\% donor $\mathrm{T}$ cell chimerism upon variable nucleotide terminal repeat analysis of blood leukocytes on day +52 post-transplant. Her post-transplant course was uneventful, other than pneumonitis of unknown etiology, cytomegalovirus reactivation with a gastric and duodenal biopsy showing CMV pathogenic effect which has responded to treatment dose valganciclovir and four infusions of IVIG, and low-level EBV viremia which regressed without any specific intervention, all occurring prior to day 100 posttransplant. She did not develop graft versus host disease and achieved transfusion-independence with normal blood counts.

\section{Discussion and conclusions}

This case illustrates the need for a heightened clinical suspicion of GATA2 haplo-insufficiency in patients who present with cytopenias and clinical evidence for immunodeficiency. This patient's initial work-up did not establish a clear diagnosis. Vitamin and mineral deficiencies that may cause pancytopenia were ruled out, and she was treated briefly with immunosuppression for a diagnosis of mild aplastic anemia without clinical

Table 3 Blood lymphocyte and dendritic cell subsets over time. $\mathrm{pDC}=$ plasmacytoid dendritic cell; $\mathrm{mDC}=$ myeloid dendritic cell

\begin{tabular}{|c|c|c|c|c|c|c|c|c|}
\hline Dates & $\begin{array}{l}\text { CD3+ } \\
\text { T-cells/uL } \\
(678-2504)\end{array}$ & $\begin{array}{l}\text { CD4+ } \\
\text { T-cells/uL } \\
(500-1500)\end{array}$ & $\begin{array}{l}\text { CD8+ } \\
\text { T-cells/uL } \\
(162-1038)\end{array}$ & $\gamma \delta \mathrm{TCR}+\mathrm{T}$-cells/uL & $\begin{array}{l}\text { CD56+ NK cells/uL } \\
(45-523)\end{array}$ & $\begin{array}{l}\text { CD19+ } \\
\text { B-cells/uL } \\
\text { (96-515) }\end{array}$ & $\mathrm{mDC} / \mathrm{uL}$ & $\mathrm{pDC} / \mathrm{uL}$ \\
\hline $11 / 2015$ & 1364 & 751 & 559 & 39 & 103 & 37 & 0 & 0 \\
\hline $12 / 2014$ & 1436 & 858 & 520 & 41 & 108 & 47 & 0 & 0 \\
\hline
\end{tabular}




\section{Patient Control}
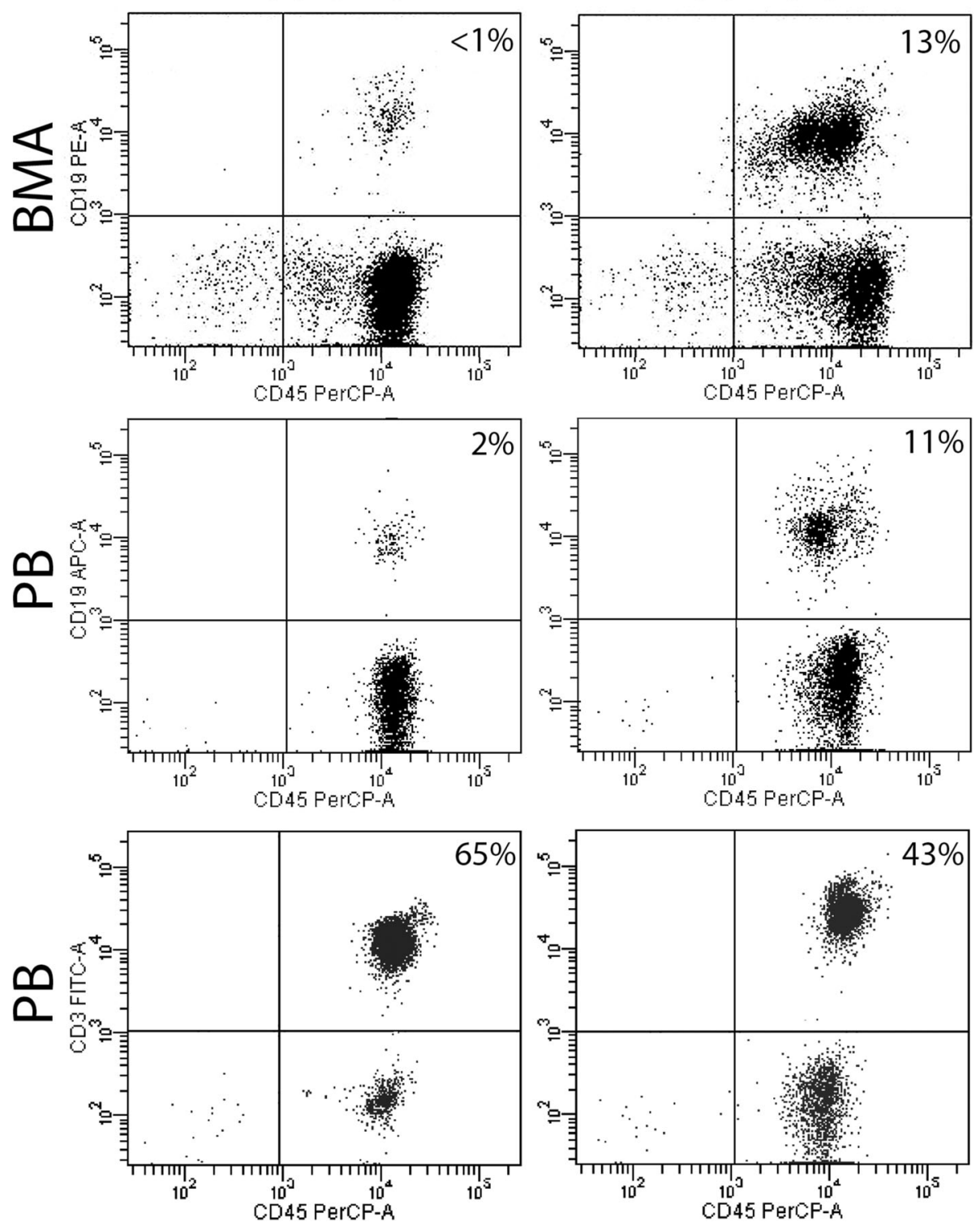

Fig. 3 Flow cytometry of bone marrow and blood showed reduced percentages of B-cells with normal frequencies of T-cells. Top row of panels: bone marrow; middle and bottom row of panels: blood. Left panels: blood and bone marrow samples from patient. Right panels: blood and bone marrow samples from a control patient, 5 years status post an allogeneic bone marrow transplant with normal levels of blood lymphocytes and no graft-versus-host disease. Flow plots show antibodies used for staining leukocytes on the $\mathrm{x}$ and $\mathrm{y}$ axes; percentages listed in the right upper quadrant of each plot show percentage of leukocytes that were CD19+ B-cells (top two rows) or CD3+ T-cells (bottom row)

improvement. The diagnosis of GATA2 can be particularly challenging due to an inconsistent relationship between genotype and phenotype and unpredictable natural history and age at the time of clinical presentation. The missense mutation detected in this patient is one among many other missense, frameshift, and nonsense mutations that result in GATA2 deficiency [3]. Of note, family members that share the same GATA2 genetic lesion may have different clinical presentations, as was presumably the case with this patient, who had more severe pancytopenia and constitutional symptoms than the other family members with medical histories of mild leukopenia, but were not genotyped. Both inherited and sporadic mutations of the GATA2 gene result in impaired self-renewal of hematopoietic progenitors, which over time progresses to cytopenias that often do not present until adulthood [9]. The risk of infectious complications in GATA2 deficiency is also unpredictable, but frequently increase in the second and third decades [9]. Allogeneic bone marrow transplantation is the only 
curative therapy for GATA2 deficiency, but is associated with significant treatment related morbidity and mortality. The decision to offer allogeneic HSCT to patients with GATA2 deficiency should be guided by the clinical presentation of the patient, donor availability, and the risk that delaying allo-HSCT until severe clinical manifestations of GATA2 deficiency develop will result in increased mortality.

What are the clinical clues that might have led to an earlier diagnosis of GATA2 deficiency in this or similar patients? In retrospect, the patient had presented with common features of GATA2 deficiency, including pancytopenia with a hypocellular bone marrow, monocytopenia, and a relative deficiency of B cells and DC in her blood and marrow [9-12]. Marrow and blood studies were consistent with a low-grade MDS with mild multilineage atypia in the marrow biopsy without increased blasts or cytogenetic abnormalities, and without a need for chronic transfusions. Her biggest complaint was her recurrent apthous ulcers with constitutional symptoms of fever and fatigue that limited her ability to work or attend school. The immunopathological findings in the bone marrow of patients with GATA2 often overlap with those of patients with myelodysplastic syndrome (MDS) since GATA2 deficiency can evolve into MDS and/or AML [3]. Bone marrow biopsies from patients with non-GATA2-related hypo-cellular MDS and GATA2 deficiency may both show presence of focal fibrosis, myeloid dysplasia, and variable numbers of CD34+ blasts, but complex cytogenetic abnormalities are more typical in hypo-cellular MDS than GATA2 deficiency $[10,13]$. Both GATA2 deficient and MDS patients may have decreased numbers of CD34+CD10+CD20+ hematagones and mature B-cells in the marrow [14], but patients with GATA2 deficiency usually have additional deficiencies of NK cells and monocytes in their marrow, and their plasma cells may express an abnormal CD19+ CD56+ phenotype [10]. While megakaryocytes with dysplastic features are increased in de novo MDS and GATA2 deficiency, the presence of both large and small megakaryocytes with separated and peripheralized nuclear lobes may provide a morphologic clue to an underlying GATA2 deficiency [10]. In this case, bone marrow findings were consistent with low-grade MDS, and the diagnosis of GATA2 deficiency was established after hematological and immunology tests showed deficiencies in numbers of blood monocytes, B-cells and dendritic cells, and GATA2 genotyping established a missense mutation. Thus, a diagnosis of GATA2 deficiency should be considered and appropriate genetic testing undertaken the setting of a patient with a new diagnosis of aplastic anemia, MDS, or immunodeficiency who presents with monocytopenia noted on the peripheral blood smear in, or B lymphopenia and decreased dendritic cells are noted upon immunophenotyping of blood leukocytes, as seen in Fig. 3.

The reduced content of B-cells in the blood and bone marrow in the face of normal serum immunoglobulin levels is notable in this case. GATA2 plays an important role in B-cell and dendritic cell development, and depletion of those cells is a characteristic feature of patients with GATA2 mutation [5, 11, 12]. Novakova et al. noted decreased numbers of immature $\mathrm{CD} 10+$ and naïve $\mathrm{B}$ cells in pediatric patients with GATA2 mutation, which was reflected in very low level of recombination excision circle (KREC) in blood and bone marrow [12]. Despite significantly reduced numbers of B-cells in blood and marrow, IgG levels were normal in a majority of patients, with increased numbers of plasma cells in their marrow [12]. This patient had mature plasma cells in the bone marrow and normal levels of immunoglobulins despite low numbers of B-cells in the blood and bone marrow (Fig. 3), consistent with published cohort studies [10, 12].

Finally, when considering allo-transplantation, the possibility of GATA2 deficiency in relatives must be considered. As noted in this case, affected family members can have a variable clinical presentation. If a HLA matched or haplo-identical related donor HSCT is being considered, immunological and genetic studies should be performed so as to exclude related with asymptomatic GATA2 genetic abnormalities.

\section{Abbreviations \\ AML: Acute myeloid leukemia; BMT: Bone marrow transplant; CBC: Complete blood count; CMV: Cytomegalovirus; DC: Dendritic cell; EBV: Epstein Barr virus; HCT: Hematopoietic Cell Transplantation; HLH: Hemophagocytic lymphohistiocytosis; HSV: Herpes Simplex Virus; IHC: Immunohistochemistry; KREC: Recombination excision circle; MCV: Mean Corpuscular Volume; MDS: Myelodysplastic syndrome; PB: Peripheral blood}

\section{Acknowledgements}

None.

Funding

National Heart, Lung, and Blood Institute, R01CA74364 to Dr. Waller.

Availability of data and materials

No referenced gene or expression array data.

Authors' contributions

All authors contributed to data collection and writing and approved the final manuscript.

Ethics approval and consent to participate

The study was conducted following institutional IRB approval of data analysis of patients undergoing allogeneic transplantation, IRB \#41106 s.

\section{Consent for publication}

The subject gave written consent to have a summary of her clinical findings presented in the case report.

Competing interests

The authors declare that they have no competing interests. 


\section{Publisher's Note}

Springer Nature remains neutral with regard to jurisdictional claims in published maps and institutional affiliations.

\section{Author details}

'Debusk College of Osteopathic Medicine, Lincoln Memorial University, Harrogate, TN 37752, USA. ²Department of Pathology, Emory University School of Medicine, Atlanta, GA 30322, USA. ${ }^{3}$ Winship Cancer Institute, Emory University, Atlanta, GA 30322, USA. Division of Bone Marrow Transplant, Aflac Cancer and Blood Disorders Center, Children's Healthcare of Atlanta, Emory University School of Medicine, Atlanta, GA 30322, USA. ${ }^{5}$ Department of Hematology/Oncology, and Pathology, Bone Marrow and Stem Cell transplantation, Emory University School of Medicine, 1365B Clifton Road, Suite B5119, Atlanta, GA 30322, USA.

Received: 4 October 2017 Accepted: 27 February 2018

Published online: 21 March 2018

\section{References}

1. Hahn CN, Chong C-E, Carmichael $\mathrm{CL}$, et al. Heritable GATA2 mutations associated with familial myelodysplastic syndrome and acute myeloid leukemia. Nat Genet. 2011;43:1012-7. https://doi.org/10.1038/ng.913.

2. Hsu AP, McReynolds LJ, Holland SM. GATA2 deficiency. Curr Opin Allergy Clin Immunol. 2015;15:104-9. https://doi.org/10.1097/ACI. 0000000000000126.

3. Spinner MA, et al. GATA2 deficiency: a protean disorder of hematopoiesis, lymphatics, and immunity. Blood. 2014;123:809-21. https://doi.org/10.1182/ blood-2013-07-515528.

4. Lim K-C, Hosoya T, Brandt W, et al. Conditional Gata2 inactivation results in HSC loss and lymphatic mispatterning. J Clin Invest. 2012;122:3705-17. https://doi.org/10.1172/JCl61619.

5. Onodera K, Fujiwara T, Onishi $Y$, et al. GATA2 regulates dendritic cell differentiation. Blood. 2016;128:508-18. https://doi.org/10.1182/blood-201602-698118.

6. Rubin TS, Zhang K, Gifford C, Lane A, Choo S, Bleesing JJ, Marsh RA. Perforin and CD107a testing is superior to NK cell function testing for screening patients for genetic HLH. Blood. 2017;129:2993-9. https://doi.org/10.1182/ blood-2016-12-753830.

7. Al-Herz W, et al. Primary immunodeficiency diseases: an update on the classification from the International Union of Immunological Societies Expert Committee for primary immunodeficiency. Front Immunol. 2014;5:1-33.

8. Russel JA, et al. Once-daily intravenous Busulfan given with Fludarabine as conditioning for allogeneic stem cell transplantation: study of pharmacokinetics and early clinical outcomes. Biology of Blood and Marrow Transplantation. 2002; 8:468-76.

9. Dickinson RE, Milne $P$, Jardine $L$, et al. The evolution of cellular deficiency in GATA2 mutation. Blood. 2014;123:863-74. https://doi.org/10.1182/blood2013-07-517151.

10. Ganapathi KA, Townsley DM, Hsu AP, et al. GATA2 deficiency-associated bone marrow disorder differs from idiopathic aplastic anemia. Blood. 2015; 125:56-70. https://doi.org/10.1182/blood-2014-06-580340.

11. Bigley V, Barge D, Collin M. Dendritic cell analysis in primary immunodeficiency. Curr Opin Allergy Clin Immunol. 2016;16:530-40.

12. Novakova M, Janda A, Wlodarski MW, et al. Defect in B cell production driven by GATA2 mutation results in their absolute reduction and mature phenotype in pediatric patients. Blood. 2014;124:2746.

13. Fohlmeister I, Fischer R, Mödder B, Rister M, Schaefer HE. Aplastic anaemia and the hypocellular myelodysplastic syndrome: histomorphological, diagnostic, and prognostic features. J Clin Pathol. 1985;38:1218-24.

14. Maftoun-Banankhah S, Maleki A, Karandikar NJ, et al. Multiparameter flow cytometric analysis reveals low percentage of bone marrow hematogones in myelodysplastic syndromes. Am J Clin Pathol. 2008;129:300-8.

\section{Submit your next manuscript to BioMed Central and we will help you at every step:}

- We accept pre-submission inquiries

- Our selector tool helps you to find the most relevant journal

- We provide round the clock customer support

- Convenient online submission

- Thorough peer review

- Inclusion in PubMed and all major indexing services

- Maximum visibility for your research

Submit your manuscript at www.biomedcentral.com/submit
) Biomed Central 